\title{
The Research about Storage and Transportation of Natural Gas Based on LNG Technology
}

\author{
Shuren Yang1, Di Xu' ${ }^{*}$, Yue Cui ${ }^{1}$, Ying Ni², Chao Duan ${ }^{3}$ \\ ${ }^{1}$ Department of Petroleum Engineering, Northeast Petroleum University, Daqing, China \\ ${ }^{2}$ China Petroleum Pipeline Bureau Tianjin Design Institute, Tianjin, China \\ ${ }^{3} \mathrm{CNOOC}$ (China) Limited Zhanjiang Branch, Zhanjiang, China \\ Email: wonderdi@sina.com
}

Received 17 March 2015; accepted 19 April 2015; published 22 April 2015

Copyright (C) 2015 by authors and Scientific Research Publishing Inc.

This work is licensed under the Creative Commons Attribution International License (CC BY). http://creativecommons.org/licenses/by/4.0/

c) (i) Open Access

\begin{abstract}
Nowadays, we are in great lack of the technology theory for the storage and transportation of gas hydrate. Under this condition, after checking out related theory of these, we established the technology roadmap of the storage and transportation of gas hydrate by LNG technology. Study has shown that the technology of LNG is more saving than that of pipeline. Then we came out with the new idea of storage and transportation of hydrate by LNG technology.
\end{abstract}

\section{Keywords}

Gas Hydrate, Composition of Produced Gas, Pretreatment Craft, LNG Technology of Storage and Transportation

\section{Introduction}

Combustible ice (natural gas hydrate) with huge reserves and more pure produced gas is a new type of clean and efficient energy. After being successful exploited, the storage and transportation of combustible ice become the most important part of industry and the vital important foundation to achieve natural gas utilization.

Currently, the technology of LNG which has become relatively mature is one of the main methods of natural gas transportation. In some conditions, long-distance transportation is more economical and convenient than that of pipeline, for the LNG volumes only 1/600 that of gas. After being liquefied in LNG liquefaction station, LNG can be transported to the destination by cryogenic tank tankers and tank trucks. Then we can store LNG in LNG

*Corresponding author. 
storage tanks. After being vaporized and measured pressure, LNG can be transported into the city pipe network.

Though combustible ice has huge reserves, its distribution is uneven. Considering this, we come out with the idea about utilizing LNG technology to store and transport combustible ice produced gas to reduce the investment of storage and transportation.

\section{Composition Characteristics of Produced Gas}

The data in Table 1 is the range of gas molecules and isotopic composition of Gas Hydrate in the following areas: Oregon coast [1], Vancouver island, Costa rice inshore coastal Sakhalin island, South Korea, the east China sea, Japan near shore, offshore, the Norwegian sea, gulf of Cadiz, Gabon, the gulf of Mexico shoreline, south Carolina, near shore, black sea, the sea of Marmara, the eastern Mediterranean, Alaska and Canada McKenzie and China Qinghai [2], etc.

From Table 1 it is not difficult to find that, gas molecules of Gas Hydrate existing in the nature mainly include $\mathrm{C}_{1}, \mathrm{C}_{2}, \mathrm{C}_{3}, \mathrm{I}-\mathrm{C}_{4}, \mathrm{n}-\mathrm{C}_{4}, \mathrm{I}-\mathrm{C}_{5}, \mathrm{n}-\mathrm{C}_{5}$, neo- $\mathrm{C}_{5}, \mathrm{cycl}_{-} \mathrm{C}_{5}, \mathrm{n}-\mathrm{C}_{6}$ and its isomer hydrocarbon gas molecules, and the conventional gas such as $\mathrm{CO}_{2}$ and $\mathrm{H}_{2} \mathrm{~S}$ molecular, then even some complex hydrate contains $\mathrm{C}_{6}+$ or $\mathrm{C}_{7}-\mathrm{C}_{9}$ heavy hydrocarbon molecules. In a word, all the characteristics of gas molecules can be roughly divided into two categories: one type of gas is composed mainly of methane $\left(\mathrm{C}_{1}>99.9 \%\right)$, containing a small amount of $\mathrm{C}_{2}$ and $\mathrm{C}_{3}$; range of another type of gas is wide, containing $\mathrm{C}_{1}-\mathrm{C}_{6}+$ paraffin, $\mathrm{CO}_{2}$ and $\mathrm{H}_{2} \mathrm{~S}$, etc.

\section{Pretreatment Process}

The process of natural gas processing is necessary when it is separated from the oil and gas field separator. Then natural gas is allowed to enter distribution pipe after processing. So this is a very significant component of natural gas industry. The pretreatment process of Gas Hydrate produced gas can consult the existing gas treatment process, as shown in Figure 1.

It should be emphasized that not all of the gas experiences the process in Figure 1. For example, if the acid component content in the produced gas is very small, which is already in line with the quality index of the natural gas commodity, it is not necessary to remove the acid gas. If ethane and heavier hydrocarbons in produced gas components are very few, the produced gas can be directly turned into liquefied natural gas (LNG) after pretreatment, etc. According to composition of Gas Hydrate, pretreatment process is mainly divided into acid process and dehydration process [3].

\begin{tabular}{|c|c|}
\hline The Gas Composition & Composition Range of Molecular \\
\hline $\mathrm{C}_{1}$ & $46.01 \%-99.999 \%(n=230)$ \\
\hline $\mathrm{C}_{2}$ & $0.00 \%-15.37 \%(n=230)$ \\
\hline $\mathrm{C}_{3}$ & $0.00 \%-21.05 \%(n=230)$ \\
\hline $\mathrm{n}-\mathrm{C}_{4}$ & $0.00 \%-9.50 \%(n=221)$ \\
\hline $\mathrm{i}-\mathrm{C}_{4}$ & $0.00 \%-5.66 \%(n=207)$ \\
\hline $\mathrm{n}-\mathrm{C}_{5}$ & $0.00 \%-0.90 \%(n=110)$ \\
\hline $\mathrm{i}-\mathrm{C}_{5}$ & $\begin{array}{c}0.00 \%-1.49 \%(\mathrm{n}=112) \\
36.01 \%(\mathrm{n}=1)\end{array}$ \\
\hline neo- $C_{5}$ & $0.00 \%-0.20 \%(\mathrm{n}=24)$ \\
\hline cycl-C ${ }_{5}$ & $0.00 \%-0.024 \%(n=13)$ \\
\hline $\mathrm{n}-\mathrm{C}_{6}$ & $0.00 \%-0.22 \%(\mathrm{n}=18)$ \\
\hline $\mathrm{C}_{6}{ }^{+}$or $\mathrm{C}_{7}-\mathrm{C}_{9}$ & $0.00 \%-1.85 \%(n=18)$ \\
\hline $\mathrm{CO}_{2}$ & $0.00 \%-27.63 \%(n=105)$ \\
\hline $\mathrm{H}_{2} \mathrm{~S}$ & $0.00 \%-2.20 \%(n=90)$ \\
\hline
\end{tabular}

$\mathrm{n}$ : Statistic number of the sample. 


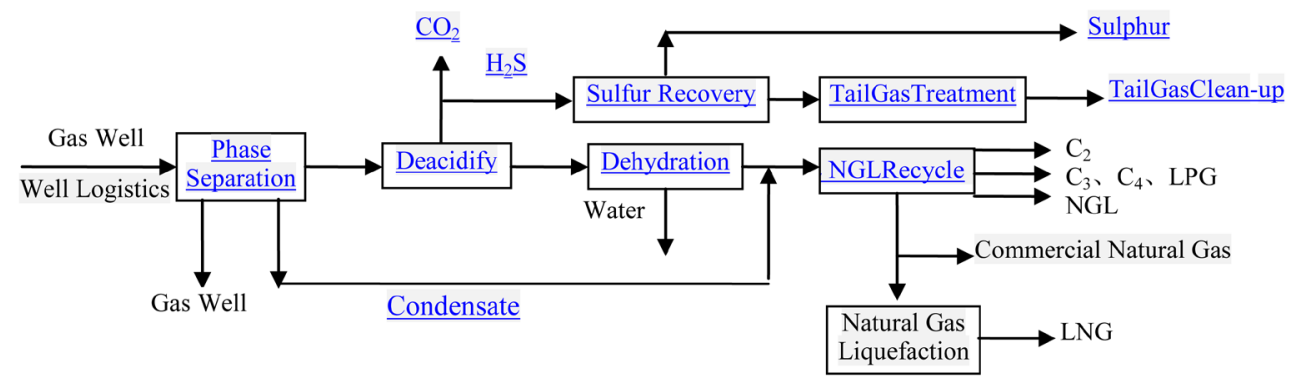

Figure 1. Schematic diagram of natural gas process.

After being pretreated the combustible ice produced gas can be stored and transported by LNG technology.

\section{LNG Technology Outline}

\subsection{Basic Properties}

The main component of liquefied natural gas (referred to as LNG) is methane. And the critical temperature is $190.58 \mathrm{~K}$, so it can't be liquefied in room temperature. After being operated by the "three off” (dehydration, hydrocarbons, acid gas removal) and being cooled (in $-162^{\circ} \mathrm{C}$ ), the natural gas can be transformed into LNG. LNG usually is stored in low temperature LNG storage tank under $-161.5^{\circ} \mathrm{C}$ in about $0.1 \mathrm{MPa}$. Then we can utilize LNG ships, tankers or pipelines to transport, and vaporize it when we need to use.

\subsection{LNG Transport Methods}

After liquefaction, the volume is only $1 / 600$ of the original. Thus, long-distance transportation is much more economical and convenient than that of pipeline in some conditions. Nowadays, the technology of LNG is in high maturity, including [4]:

1) Maritime vessels transportation: used in international trade, $12-16 \times 10^{4} \mathrm{~m}^{3}$ per time.

2) Motor transportation: used in land transportation about $200-1000 \mathrm{~km}, 27-40 \mathrm{~m}^{3}$ per time.

3) Train transportation: used in land transportation with long distance (1000 - $4000 \mathrm{~km})$ by tank containers, $40-80 \mathrm{~m}^{3}$ per time.

\subsection{LNG's Advantage}

1) It's propitious to transport in long distance economically.

2) High storage efficiency covers an area of less saving investment.

3) It's convenient to regulate the gas load.

4) It can be used as quality vehicle fuel.

5) It's propitious to protect the environment. Because the combustion emission of natural gas contains much less $\mathrm{SO}_{2}, \mathrm{NO}_{\mathrm{x}}$, and greenhouse gases, so the environment pollution of natural gas is much less than that of coal and petroleum (shown in the following Table 2).

6) It’s propitious for market discipline and orderly competition.

\subsection{Liquefaction Process}

LNG liquefaction processes have different types. With cooling methods it can be divided into the following three ways: cascade liquefaction process; mixed refrigerant liquefaction process; liquefaction process with expander. It should be noted that such division isn't critical and it is commonly used in certain part in composite of different combination including various liquefaction processes.

Table 2. The variety of carbon emissions of different fossil fuel in the same amount of heat.

\begin{tabular}{ccccccccc}
\hline NG & LNG & Gasoline & Kerosene & Diesel & Crude & Heavy & Bituminous coal & Anthracite \\
\hline 0.61 & 0.71 & 0.80 & 0.82 & 0.84 & 0.84 & 0.88 & 1.09 & 1.14 \\
\hline
\end{tabular}


1) Cascade liquefaction processes

Advantages: It needs low energy consumption; refrigerant is the pure substance with no matching problem. The technology is mature with stable operation.

Disadvantages: multi-unit in complex process; more ancillary equipment and, needing specialized in the production and a variety of steerages devices refrigerants; pipeline and control system in great complexity with inconvenience maintenance [4].

2) Mixed refrigerant liquefaction process

Advantages: less unit equipment, more simple the process, lower investment, low investment costs than the classic cascade liquefaction process about $15 \%$ to $20 \%$; easy to manage. Mixed refrigerant components can be extracted from natural gas and supplement partially or completely.

Disadvantages: higher energy consumption (higher than cascade liquefaction process about 10\% to 20\%; more difficult reasonable proportion mixed refrigerant; flow calculation of the components required to provide reliable data and the physical parameters of the balance [4].

3) Liquefaction process with expander

Advantages: more simple process, more flexible adjustment, more reliable work, much easier to start, much easier to operate and more easier to maintain; When we use natural gas as the working fluid, the specialized production, transportation, storage refrigerant costs can be saved.

Disadvantages: The air must be full depth dry before convey to the device. Reflux pressure is low. The demand of heat transfer area is larger. The equipment must be put into large metal. It's limited by the user number of low pressure. In the condition of low liquefaction rate, after increasing the number of recycle compressor, the power consumption is substantially increased.

\subsection{Gasification Process}

The technology of LNG vaporization station is broadly divided into two types: One is boil-off gas (BOG) re-liquefaction process; another is BOG direct compression process. There is no essential difference between the two processes. There is just a little difference in the boil-off gas treatment process. The figure below shows the process of LNG gasification station by BOG re-liquefaction. LNG can be transported downstream after be gasified in gasification station. It is showed in the Figure 2.

\section{Simulation of HYSYS Liquefaction Process}

To increase the feasibility of the process, we use HYSYS to build simulation model. After entering the gas composition, temperature and pressure conditions known and the initial process parameters, we need to determine the parameters of the process and equipment required to comply with the restrictions. The computational model of HYSYS is shown in Figure 3.

\subsection{Basic Parameters}

1) Raw material gas flow rate $1944 \mathrm{kmol} / \mathrm{h}$.

2) Gas Temperature: $35^{\circ} \mathrm{C}$.

3) Gas pressure: $5500 \mathrm{kPa}$.

Natural gas composition and mixed refrigerant composition are showed in Table 3 and Table 4.

\subsection{The Influence on Yield and Total Energy Consumption from LNG Storage Pressure}

This process is stored under pressure at a temperature of 600 - $700 \mathrm{kPa}$ when the total energy consumption is not

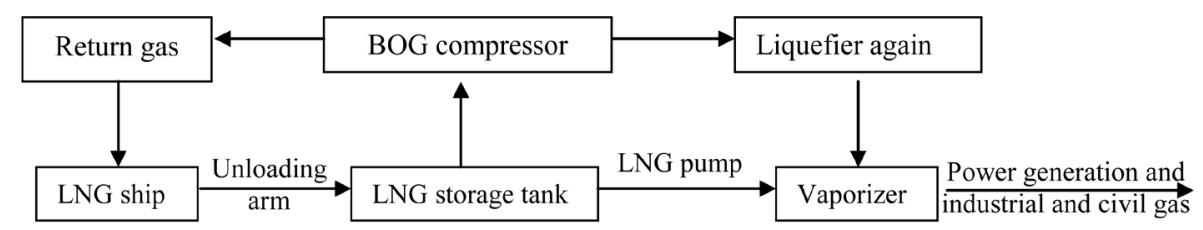

Figure 2. LNG station process. 
high while natural gas liquefaction rate has reached more than $80 \%$. So it can be used as a reference design LNG storage pressure range. The simulation results as shown the Figure 4.

\subsection{Impact on the Energy Consumption of Mixed Refrigerant Composition}

Table 5 shows that if we can make butane and nitrogen maintained in a substantially constant composition reduce the methane content in the refrigerant and increase ethane, propane component, the amount of circulation of refrigerant required can be significantly reduced. Then the total energy consumption can also be reduced, and the yield LNG rate is only slightly reduced, remained above $85 \%$. By screening, the sixth computing mixed refrigerant flow is the best choice.

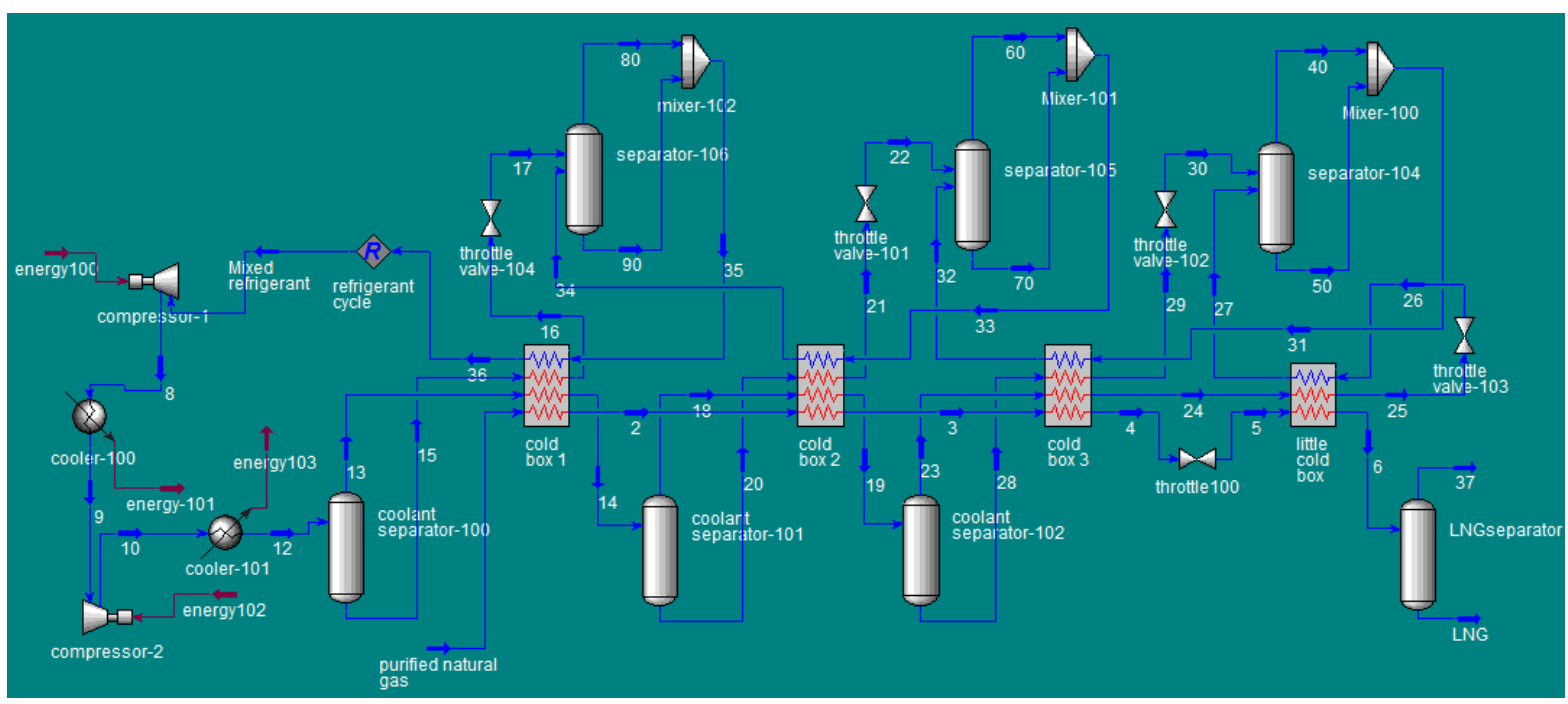

Figure 3. Closed mixed refrigerant flow simulation.

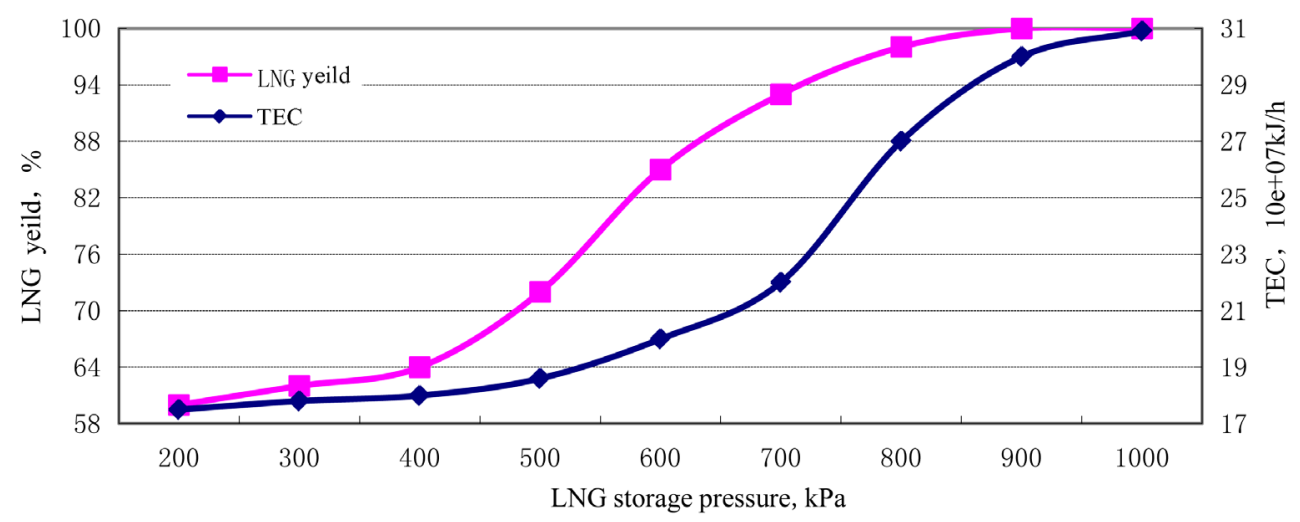

Figure 4. LNG storage pressure effects on yield and total energy consumption.

Table 3. Raw natural gas composition.

\begin{tabular}{ccccccccc}
\hline Constituent & $\mathrm{CH}_{4}$ & $\mathrm{C}_{2} \mathrm{H}_{6}$ & $\mathrm{C}_{3} \mathrm{H}_{8}$ & $\mathrm{i}-\mathrm{C}_{4} \mathrm{H}_{10}$ & $\mathrm{n}-\mathrm{C}_{4} \mathrm{H}_{10}$ & $\mathrm{~N}_{2}$ & $\mathrm{CO}_{2}$ & Sum \\
\hline Ingredient \% (mol) & 80.0 & 10.20 & 3.1 & 1.20 & 0.62 & 0.58 & 4.3 & 100.00 \\
\hline
\end{tabular}

Table 4. Mixed refrigerant composition.

\begin{tabular}{cccccccc}
\hline Constituent & $\mathrm{CH}_{4}$ & $\mathrm{C}_{2} \mathrm{H}_{6}$ & $\mathrm{C}_{3} \mathrm{H}_{8}$ & $\mathrm{i}-\mathrm{C}_{4} \mathrm{H}_{10}$ & $\mathrm{n}-\mathrm{C}_{4} \mathrm{H}_{10}$ & $\mathrm{~N}_{2}$ & Sum \\
\hline Ingredient \% (mol) & 29.4 & 33.4 & 26.7 & 4.6 & 3.4 & 2.5 & 100.00 \\
\hline
\end{tabular}


Table 5. The influence of composition of mixed refrigerant for energy consumption.

\begin{tabular}{|c|c|c|c|c|c|c|c|c|}
\hline & \multicolumn{6}{|c|}{ Mixed refrigerant composition (\%, mol) } & \multirow{2}{*}{ Refrigerant circulation amount (kmol/h) } & \multirow{2}{*}{ Total energy $(10 \mathrm{e}+07 \mathrm{~kJ} / \mathrm{h})$} \\
\hline & $\mathrm{CH}_{4}$ & $\mathrm{C}_{2} \mathrm{H}_{6}$ & $\mathrm{C}_{3} \mathrm{H}_{8}$ & $\mathrm{i}-\mathrm{C}_{4} \mathrm{H}_{10}$ & $\mathrm{n}-\mathrm{C}_{4} \mathrm{H}_{10}$ & $\mathrm{~N}_{2}$ & & \\
\hline $1^{\text {st }}$ & 70 & 10 & 10 & 3.60 & 3.40 & 3.00 & 78,650 & 78.6 \\
\hline $2^{\text {nd }}$ & 60 & 15 & 15 & 4.60 & 3.40 & 2.00 & 25,470 & 54.4 \\
\hline $3^{\text {rd }}$ & 50 & 15 & 25 & 4.60 & 3.40 & 2.00 & 17,560 & 30.7 \\
\hline $4^{\text {th }}$ & 40 & 25 & 25 & 4.60 & 3.40 & 2.00 & 10,420 & 27.5 \\
\hline $5^{\text {th }}$ & 30 & 38 & 22 & 4.60 & 3.40 & 2.00 & 7850 & 24.2 \\
\hline $6^{\text {th }}$ & 33 & 35 & 22 & 4.60 & 3.40 & 2.00 & 6290 & 17.3 \\
\hline
\end{tabular}

After simulated calculation liquefaction process systematically, we obtain the process parameters of each node in the whole process, quantitative analysis of the impact of important process parameters on process performance, accordingly reduce energy consumption and increase the feasibility of the process.

\section{Conclusions}

1) The technology of LNG which is one of the main transportation methods of natural gas has become relatively mature. In some conditions, long-distance transportation is much more economical and convenient than that of pipeline, for the LNG volumes only 1/600 that of gas-phase.

2) The investment of LNG facilities needs more cost, and the operation condition is special. The operating pressure varies from high pressure to low pressure (atmospheric pressure), and the operating temperature varies from ambient temperature to $-162^{\circ} \mathrm{C}$ or from $-162^{\circ} \mathrm{C}$ to ambient temperature, which requires production equipment and materials, must be adapted to such operating conditions and facilities must be in strict demanding.

3) With cooling methods it can be divided into the following three ways: cascade liquefaction process; mixed refrigerant liquefaction process; liquefaction process with expander. Combustible ice produced gas can be stored and transported by one or more LNG complex processes.

\section{Fund}

The source of the project: Supported by Northeast Petroleum University Innovation Foundation for Postgraduate. The project number: YJSCX2014-014NEPU.

\section{References}

[1] Milkov, A.V., Claypool, G.E., Lee, Y.J., et al. (2005) Gas Hydrate Systems at Hydrate Ridge Offshore Oregon Inferred from Molecular and Isotopic Properties of Hydrate-Bound and Voidgases. Geochimica et Cosmochimica Acta, 69, 1007-1026. http://dx.doi.org/10.1016/j.gca.2004.08.021

[2] Lu, Z.Q., Zhui, Y.H., Zhang, Y.Q., et al. (2010) Gas Formation Study of Gas Hydrates in Qilian Mountain Regions of Qinghai Province. Modern Geology, 24, 581-588.

[3] Wang, K.Y. (2005) Natural Gas Purification Process: The Decarburization Desulfurization, Dehydration, Sulfur Recovery and Tail Gas Treatment. Petroleum Industry Press, Beijing.

[4] Gu, A.Z., et al. (2004) LNG Technology. Mechanical Industry Press, Beijing. 